\title{
Differing Effects of Cabbage Defense Responses Induced by MEAM1 and MED Cryptic Species of Bemisia Tabaci on Later-Arriving Conspecifics and Heterospecifics
}

\section{Youjun Zhang ( $\nabla$ zhangyoujun@caas.cn )}

Chinese Academy of Agricultural Sciences Institute of Vegetables and Flowers https://orcid.org/00000003-3508-6695

Jie $\mathrm{Hu}$

Hubei University

Jintian Lu

Hubei University

Nina Yang

Hubei Academy of Agricultural Sciences

Baiming Liu

Tianjin Academy of Agricultural Science

Peiyi Fu

Hubei University

Jinjian Yang

Hubei University

Xiaoguo Jiao

Hubei University

\section{Research Article}

Keywords: Bemisia tabaci, plant induced response, total phenol, induced defense, cabbage, plantmediated interaction

Posted Date: September 13th, 2021

DOI: https://doi.org/10.21203/rs.3.rs-818481/v1

License: (c) (1) This work is licensed under a Creative Commons Attribution 4.0 International License. Read Full License 


\section{Abstract}

Two cryptic species of the Bemisia tabaci species complex, MEAM1 (Middle East-Asia Minor 1) and MED (Mediterranean), are highly destructive herbivores. Attack by herbivorous insects often induces defense responses in plants, including the accumulation of toxic secondary metabolites, the synthesis of herbivore-induced plant volatiles (HIPVs) and defensive proteins, and the release of volatile organic compounds that attract natural enemies. These defense responses, which often differ depending on the herbivore, may affect the preference and performance of later-arriving con- and heterospecific whiteflies that attack the same plant. In the present study, we found that MEAM1 whiteflies preferred settling and ovipositing on non-infested and MED-infested cabbage over MEAM1-infested cabbage plants, but that MED whiteflies showed no significant difference in settling or oviposition preference among non-infested, MEAM1-infested, and MED-infested plants. MEAM1 infestation increased the contents of total phenols and flavonoids in cabbage, which coincided with the increased expression of the following genes in the phenylpropanoid biosynthesis pathway: $P A L 2, C 4 H$, and $4 C L 1$. Soluble protein contents were also markedly higher in the MEAM1-infested cabbage plants than in the non-infested and MED-infested cabbage plants. Overall, these results demonstrate that previous infestation by MEAM1 and MED whiteflies induced defense responses in cabbage plants that had different effects on the host preference and performance of later-arriving con-and heterospecific whiteflies. Phenolic compounds may be the key factors influencing host choice by MEAM1 and MED whiteflies on cabbage plants.

\section{Key Messages}

- MEAM1 (Middle East-Asia Minor 1) and MED (Mediterranean) of Bemisia tabaci species complex are two most invasive pests around the world.

- Cabbage defense responses induced by MEAM1 and MED are species-specific and such specificity shape the asymmetric effects on later-arriving conspecifics and heterospecifics.

- MED previous infestation facilitated later-arriving heterospecific MEAM1.

- Cabbages previously infested by MEAM1 accumulated phenol and were more resistant to subsequent conspecifics.

- Phenolic compounds may be the key factor mediating asymmetric effects of pre-infestation on subsequent host choice between MEAM1 and MED.

\section{Introduction}

Plants in natural environments are frequently attacked by a wide range of herbivores (Karban and Baldwin 1997). In response, plants have developed sophisticated defense mechanisms, some of which are expressed constitutively whereas others are induced by herbivore infestation (Walling 2000; Kessler and Baldwin 2002; Chen 2008). The induced defenses of plants include the accumulation of secondary metabolites that directly affect insect behavior and performance, and the emission of volatiles that indirectly recruit natural enemies to the infested plants (Howe and Jander 2008). The combined effects of 
direct and indirect defenses provide durable resistance to a broad spectrum of arthropod herbivores in natural ecosystems (Ferry et al. 2004). The induced responses of host plants generally depend on precise perception of various stimulants from attackers, followed by a set of signal transduction cascades that transcriptionally reprogram the plant to activate efficient defense pathways (Stahl et al. 2018). Salicylic acid (SA) and jasmonic acid (JA), two phytohormones that modulate inducible defenses, commonly interact both synergistically and antagonistically (Beckers and Spoel 2006). The crosstalk between SA and $\mathrm{JA}$ is considered an important factor that influences the interaction between host plants and herbivore insects (Koornneef and Pieterse 2008). It is well established that leaf-chewing insects mainly activated JA-dependent defenses, whereas piercing-sucking insects and biotrophic pathogens activate SA-dependent defenses (Erb et al. 2012; Pieterse et al. 2012).

Research with many plant species has revealed a great variety of small molecules with toxic or antinutritive effects on arthropod herbivores. Phenolics, for example, are well known for their toxic effects on herbivorous insects (Close and Mcarthur 2002). They encompass a large and diverse group of aromatic compounds, including simple phenols, phenolic acids, flavonoids, and others (Dixon et al. 2002). Glucosinolates (GS), another main group of insect-resistant secondary metabolites in the Brassicaceae, have been shown to confer resistance to a wide range of generalist herbivores (Hopkins et al. 2009). Many terpenoids, the most metabolically diverse class of plant volatile organic compounds (VOCs), may also provide a direct defense against herbivorous insects or an indirect defense by recruiting the parasitoids and predators of herbivorous insects (Dudareva et al. 2013). In addition, well-studied classes of plant secondary metabolites with defensive properties include alkaloids (e.g., nicotine, caffeine, and cocaine) and defensive proteins (e.g., proteinase inhibitors, superoxide dismutase, and peroxidases) (Mauch-Mani et al. 2017).

Adaptive strategies of plants induced by herbivorous insects also include changes in plant nutrients (Awmack and Leather 2002; Gripenberg et al. 2010). Studies on host nutrition have mainly focused on nitrogen $(\mathrm{N})$ and phosphorus $(\mathrm{P})$, which have significant effects on the performance of herbivorous insects (Lu et al. 2007; Visanuvimol and Bertram 2010). Some nitrogenous compounds, including total amino acids, are also considered to be required for the growth and development of herbivorous insects (Aqueel et al. 2014).

It seems likely that most plants accumulate toxic secondary metabolites as part of their induced defenses against herbivores (Schuman and Baldwin 2016). As a result, the nutritional value of herbivoredamaged plants may be inferior to that of non-damaged plants such that the herbivore-damaged plants have a reduced probability of being attacked by herbivores (Kessler and Halitschke 2007). These efficient induced plant defenses likely impose a selection pressure on herbivorous insects, which in turn may develop sophisticated ways to cope with plant resistance (Karban and Agrawal 2002). Increasing evidence has revealed that some herbivores manipulate plant defenses to improve the quality of host plants for their own benefit (Walling 2008). For instance, some sap-sucking insects, including whiteflies, manipulate host plant metabolism by inducing SA-dependent defenses to suppress the antagonistic JAmediated defense pathways (Zarate et al. 2007; Zhang et al. 2013). In general, JA-dependent defenses 
play a major role in regulating the synthesis of secondary metabolites and the emission of VOCs (De Geyter et al. 2012). As a consequence of the manipulation, plants previously infested by herbivorous insects may become more susceptible than non-infested plants (Poelman and Dicke 2014). When two herbivores share a host, the plant defense responses induced by the early-arriving herbivore may have significant effects on the preference and performance of the later-arriving herbivore (Stam et al. 2014).

MEAM1 (Middle East-Asia Minor 1, "B" biotype) and MED (Mediterranean, "Q" biotype), two sibling species in the Bemisia tabaci species complex (Gennadius) (Homoptera:Aleyrodidae), are important invasive whiteflies of agriculture and horticulture crops worldwide (Oliveira et al. 2001; Dinsdale et al. 2010; Esterhuizen et al. 2013). These whiteflies damage plants not only by directly sucking phloem sap and excreting honeydew, but also by transmitting plant viruses (Inbar and Gerling 2008). Previous studies have demonstrated that $B$. tabaci suppresses the most effective JA-mediated plant defenses by inducing SA-dependent defenses in Arabidopsis, lima been, and tomato (Kempema et al. 2007; Zhang et al. 2009; Zhang et al. 2013). Although MEAM1 and MED have developed sophisticated strategies to modulate plant-induced resistance, there is some evidence that they differ greatly in their preference for and performance on different host plants (Jiao et al. 2012; 2013). MEAM1, for example, has a greater preference for cabbage plants (Brassica oleracea) than MED and performs better on cabbage plants than MED, but the underlying mechanism is largely unexplored (lida et al. 2009; Jiao et al. 2014).

The changes in herbivore-induced plant defenses may be qualitatively and quantitatively affected by many factors, such as the species of attacking arthropod and its feeding guilds, or the sequence of insects that colonize a plant (Poelman et al. 2008; Erb et al. 2011; Viswanathan et al. 2007). Considering that MEAM1 and MED are two distinct herbivore species, we suspect that the defenses induced by MEAM1 or MED are species-specific, i.e., the defenses induced by MEAM1 or by MED will have different effects on the preference and performance of later-arriving conspecific vs. heterospecific whiteflies.

In the present study, we (1) compared the settling and ovipositing choice of MED and MEAM1 on noninfested cabbage plants (Brassica oleracea var. Jingfeng 1), MEAM1-infested cabbage plants, and MEDinfested cabbage plants; (2) determined the content of total phenolics and flavonoids and the relative expression of genes involved in the phenolic biosynthesis pathway of cabbage leaves infested by MED or MEAM1; and (3) assessed the main biochemical properties in MED-infested and MEAM1-infested cabbage. We found that cabbage previously infested by MED promoted subsequent infestation by MEAM1. Prior MEAM1 infestation, in contrast, had negative effects on later-arriving MEAM1 and MED. We also found that the contents of total phenols and flavonoid induced by MEAM1 and MED differ significantly, which may mediate the preference and performance of later-arriving conspecifics and heterospecifics. These results reveal that MEAM1 and MED, even though they have similar feeding modes, tend to induce different defensive responses in cabbage plants and therefore can be expected to have asymmetric effects on each other's performance. This new information should assist in the development of pest management strategies.

\section{Materials And Methods}




\subsection{Insects and host plants}

The MEAM1 cryptic species of $B$. tabaci was originally collected from cabbage (Jingfeng 1 ) in 2004, and the MED cryptic species of $B$. tabaci was originally obtained from poinsettia (Euphorbia pulcherrima) in 2008 in Beijing. The two species were maintained on tomato (Lycopersicon esculentum var. Zhongza 9) in separate greenhouses. For use in experiments and assays, stock cultures of MEAM1 and MED were maintained on tomato in separate insect-proof screened cages $(60 \times 60 \times 60 \mathrm{~cm})$ in the laboratory at 23 $\pm 2^{\circ} \mathrm{C}, 60 \pm 10 \% \mathrm{RH}$, and a $14 \mathrm{~L}: 10 \mathrm{D}$ photoperiod. The identity and purity of the cultures were monitored every 2-3 generations using the random amplified polymorphic DNA-polymerase chain reaction (RAPDPCR) technique (Chu et al. 2007). Cabbage (Jingfeng 1) was grown from seed in a greenhouse at $23 \pm$ $2{ }^{\circ} \mathrm{C}$ and with natural lighting. Two weeks after seeds were sown, seedlings were transplanted into $5-\mathrm{cm}-$ diameter plastic pots (one seedling per pot). All the plants were fertilized once each week, and all plants were free from pests and pathogens. When they had six main leaves, plants of similar size were selected for the experiments. The experiments included three treatments with cabbage plants: MEAM1-infested plants, MED-infested plants, and non-infested plants. Infested plants were obtained by attaching two clipcages per plant with 50 MEAM1 or MED whiteflies per clip-cage. The non-infested cabbage plants were treated in the same manner, but whiteflies were not added to the clip-cages. After the cabbage plants were infested (or not infested) by MEAM1 and MED whiteflies for $72 \mathrm{~h}$, they were selected for the settling and oviposition preference experiment (Sect. 2.2), for chemical analysis (Sect. 2.3), and for gene expression analysis (Sect. 2.4).

\subsection{Settling and oviposition preference of MEAM1 and MED whiteflies on non-infested, MEAM1-infested, and MED-infested cabbage plants}

An experiment concerning whitefly settling and oviposition preference was conducted as described by Jiao et al. $(2012,2014)$. In brief, three cabbage plants (one plant from each treatment) were placed in a screen cage $(60 \times 60 \times 60 \mathrm{~cm})$. The three cabbage plants (MEAM1-infested, MED-infested, and noninfested) were arranged in the form of an even-sided triangle with $20-\mathrm{cm}$ sides so that their leaves did not touch. About 200 MEAM1 or MED whiteflies were collected between 07:00-08:00 h and released from an aspirator into the center of the screen cage above the plant canopy. The aspirator sampling bottle containing whiteflies was held inside a clear plastic tumbler that hung at the center of the cage about 30 $\mathrm{cm}$ above the plant canopy. The whiteflies moved to the open top of the sampling bottle and flew away to approach the plants from above. The number of whiteflies on each plant was determined after 12, 24, 36, $48,60,72,84,96,108$, and $120 \mathrm{~h}$. To prevent whiteflies from moving between leaves and different plants during counting, the whiteflies were counted under dim light just before 07:00 and just after 19:00. At the end of the settling assay, all leaves from each cabbage plant were removed and a dissecting microscope was used to determine the number of eggs laid (an indicator of oviposition preference) on each replicate plant. For each whitefly species, the settling and oviposition preference experiment was replicated six times. 


\subsection{Chemical analysis of non-infested, MEAM1-infested, and MED-infested cabbage plants}

Cabbage plants were infested with MEAM1 and MED whiteflies or were not infested as described in Sect. 2.1. After the cabbage plants were infested or not infested for $72 \mathrm{~h}$, leaves adjacent to the clip cages were selected for chemical analysis. A 15-g sample (fresh weight) of leaves was collected from each of three replicate plants of each treatment. About one-third of each sample was dried at $80^{\circ} \mathrm{C}$ for $72 \mathrm{~h}$ in a drying oven and was used for determination of total phenol and flavonoid contents. Another one-third of each sample was not dried and was used for determination of free protein and total amino acid contents. Total phenol, flavonoids, free protein, and total amino acids were assayed according to the reagent label directions (Nanjing jiancheng Ltd. Co., Nanjing, Jiangsu Province, China). The final one-third of each sample was dried at $80^{\circ} \mathrm{C}$ for $72 \mathrm{~h}$ and was used for determination of total nitrogen $(\mathrm{N})$ and phosphorus $(\mathrm{P})$ with a $\mathrm{CNH}$ analyzer (Model ANCA-nt; Europa Elemental Instruments, Okehampton, UK). The measure of each biochemical component was repeated five times for each treatment.

\subsection{Gene expression analysis of non-infested, MEAM1- infested, and MED-infested cabbage plants}

Quantitative reverse-transcriptase polymerase chain reaction (qRT-PCR) was used to determine the effects of the three treatments on the relative expression levels of the following marker genes in the phenylpropanoid biosynthesis pathway: PAL2 (Phenylalanine ammonia lyase 2), C4H(Cinnamate hydroxylase), 4CL 1 (4-coumarate COA ligase 1), and CHI (Chalcone isomerase). Infested and non-infested cabbage plants were obtained as described in the previous sections. Leaves were obtained as described in Sect. 2.3, and total RNA was extracted from the leaves using TRIzol Reagent (Invitrogen) following the manufacturer's instructions. A 2- $\mu$ g quantity of total RNA was used for cDNA synthesis, and $1 \mu$ of 20times-diluted cDNA served as a template for a $20-\mu$ l qRT-PCR that used the Hieff UNICON® Power qPCR SYBR Green Master Mix (Yeasen Biotech) and the Applied Biosystems 7300 real-time PCR system. The sequences of specific primers used for each gene are indicated in Table 1. Actin was used as a reference gene. There were four technical replicates for each reaction, and the data were analyzed by the $2^{-\Delta \Delta C t}$ method (Schmittgen and Livak 2008). Relative expression levels were log-transformed, and the effects of the treatments were separately tested for each gene using one-way ANOVAs; when ANOVAs were significant $(P<0.01)$, treatment means were compared with a post-hoc test. 
Table 1

The sequences of specific primers used for qPCR.

\begin{tabular}{|lll|}
\hline Gene & Forward primer $\left(\mathbf{5}^{\prime} \mathbf{3}^{\prime} \mathbf{)}\right.$ & Reverse primer $\left(\mathbf{5}^{\prime} \mathbf{3}^{\prime} \mathbf{)}\right.$ \\
\hline PAL2 & AGTTCACCGATCATCTAACG & CTAGCTTCATGTACGAGCTT \\
\hline $4 C L 1$ & GAGGTTCCTTAGAGGCTACTTG & CCTCGTTGATCTCTCCCTTCTGTT \\
\hline CHI & CGGAGAACTGTGTGGCGATA & AGAGCGAAGAGGATGGATGC \\
\hline Actin & CTATTGAGCATGGTGTTGTGAGC & TAGCTGGAGAGTTGAAGGTTTCG \\
\hline
\end{tabular}

\subsection{Statistical analyses}

SPSS (version 13.0; SPSS Inc., Chicago, IL, USA) was used for statistical analysis. Homogeneity of variance and normality were checked using the Levene test and the Shapiro-Wilk test, respectively. For each whitefly species, the effects of the three treatments on settling preference among were tested by a repeated-measures ANOVA (RMANOVA). For each whitefly species, the effects of the three treatments on female oviposition preference were tested with a one-way ANOVA. The effects of the treatments on the biochemical components (total phenol, flavonoids, total amino acid, soluble protein, total $\mathrm{N}$, and total $\mathrm{P}$ ) and on the relative expression of genes in the phenylpropanoid biosynthesis pathway were determined with one-way ANOVAs. Tukey's test was used to separate means when the effect of treatment was significant.

\section{Results}

3.1 Settling and oviposition preference of MEAM1 and MED whiteflies as affected by prior infestation by conspecific or heterospecific whiteflies

MEAM1 whiteflies preferred settling (RMANOVA, $F_{2,15}=4.677, P=0.026$, Fig. $1 \mathrm{~A}$ ) and ovipositing (one-way ANOVA, $F_{2,15}=3.784, P=0.047$, Fig. $2 A$ ) on the non-infested and the MED-infested cabbage plants over the MEAM1-infested cabbage plants. However, there were no significant differences in the settling preference (RMANOVA, $F_{2,15}=0.755, P=0.487$, Fig. $1 B$ ) or oviposition preference (one-way ANOVA, $F_{2,15}=0.585, P=$ 0.569 , Fig. 2B) of MED whiteflies among the three treatments.

\subsection{Biochemical properties of non-infested, MEAM1- infested, and MED-infested cabbage plants}

The total phenol content (one-way ANOVA, $F_{2,12}=96.406, P<0.001$; Fig. $3 A$ ), flavonoid content $\left(F_{2,12}=12.599, P<0.001\right.$; Fig. $\left.3 B\right)$, and soluble protein content $\left(F_{2,12}=8.169, P=0.006\right.$; Fig. $\left.4 A\right)$ were markedly higher in the MEAM1-infested than in the non-infested and MED-infested cabbage plants. However, there were no significant differences in the contents of total amino acids $\left(F_{2,12}=2.36, P=0.137\right.$; 
Fig. 4B), total $N\left(F_{2,12}=0.340, P=0.718\right.$; Fig. $\left.4 C\right)$, or total $P\left(F_{2,12}=0.415, P=0.670\right.$; Fig. $\left.4 D\right)$ in the cabbage plants among the three treatments.

\subsection{Relative expression level of marker genes in the phenylpropanoid biosynthesis pathway in non- infested, MEAM1-infested, and MED-infested cabbage plants}

After $72 \mathrm{~h}$ of infestation, the transcript levels of PAL2 $\left(\mathrm{F}_{2,6}=231.510, \mathrm{P}<0.001\right.$; Fig. $\left.5 \mathrm{~A}\right), C 4 \mathrm{H}$ $\left(F_{2,6}=106.204, \mathrm{P}<0.001\right.$; Fig. $\left.5 \mathrm{~B}\right)$, and $4 C L 1\left(\mathrm{~F}_{2,6}=92.201\right.$, $\mathrm{P}<0.001$; Fig. $\left.5 \mathrm{C}\right)$ were significantly higher in MEAM1-infested cabbage plants than in the non-infested and MED-infested cabbage plants. However, there were no differences in the expression levels of $\mathrm{CHI}\left(\mathrm{F}_{2,6}=1.390, \mathrm{P}=0.319\right.$; Fig. 5D) among the three treatments.

\section{Discussion}

Herbivore-induced defenses are important aspects of plant-insect interactions. By using a combination of behavioral assays, molecular analysis, and chemical analysis in the current study, we determined the effects of cabbage plant defensive responses on the preference and performance of MEAM1 and MED whitefly species that commonly coexist in the field. The behavioral assays showed that MEAM1 avoided settling and ovipositing on MEAM1-infested cabbage plants and preferred to settle and oviposition on cabbage plants that were non-infested or previously infested by MED. MED females showed no settling or oviposition preference among non-infested, MED-infested, and MEAM1-infested cabbage plants. In addition, the high levels of total phenols and flavonoids induced by MEAM1 were consistent with the increased expression of PAL2, C4H, and $4 C L 1$ genes, which are markers of the phenylpropanoid biosynthesis pathway. It seems likely that phenolic compounds may mediate the asymmetric effects of preinfestation on subsequent host choice between MEAM1 and MED. Our results suggest that the herbivore-induced defenses in cabbage differ between MEAM1 and MED and that infestation by earlyarriving species could facilitate or hamper the later-arriving con- and heterospecifics.

Previous studies have confirmed that plants previously exposed to MEAM1 become less suitable for laterarriving herbivores, which experience lower survival rates and reduced population growth. For example, survival of the aphid Myzus persicae was lower on tobacco plants previously infested by MEAM1 nymphs than on non-infested tobacco plants (Xue et al. 2010). Similarly, the survival of nymphs of the whitefly Trialeurodes vaporariorum was lower on tomato plants previously infested with MEAM1 than on non-infested tomato plants (Zhang et al. 2014). In the present study, MEAM1 preferred to settle on cabbage plants previously infested by MED over MEAM1-infested plants. Our results indicate that cabbage plants infested with MEAM1 had detrimental effects on subsequent conspecifics. This reduced settling of MEAM1 on MEAM1-infested plants may result from the accumulation of toxic secondary metabolites induced by MEAM1. Infestation by MEAM1, for instance, significantly increased the activity of host defensive enzymes and reduced M. persicae survival and fecundity on tobacco (Zhao et al. 2015). Attack by MEAM1 caused collards to accumulate high levels of pathogenesis-related proteins that are considered to provide defense against larvae of the cabbage looper (Inbar et al. 1999). 
Glucosinolates (GS), the main insect-resistant secondary metabolites in the Brassicaceae, have been shown to confer resistance to a wide range of generalist herbivorous insects. However, accumulating evidence indicated that GS in general has limited effect on the performance of piercing-sucking insects, including whitefly and aphid (Li et al. 2021; Yang et al. 2020; De Vos and Jander 2009). Our previous results have shown that phenolics, insect-resistant secondary metabolites produced by different plants, are the key factor that mediate the host choice of MEAM1 and MED on cabbage (Yang et al. 2020). In the current study, biochemical assays indicated that the contents of total phenols, including flavonoids, were significantly higher in MEAM1-infested cabbage plants than in MED-infested or non-infested cabbage plants. The high level of total phenols and flavonoids is consistent with the increased expression of PAL2, $C 4 H$, and $4 C L 1$ genes, which are markers of the phenylpropanoid biosynthesis pathway. These findings are consistent with the studies of Cui et al. (2012), who reported that previous infestation by MEAM1 decreased the nutrient contents and increased the total phenolics in tomato plants and thereby reduced the fitness of later-arriving whiteflies. Similarly, 20 days of infestation by MEAM1 nymphs induced significant increases in the phenolic contents in wild tobacco plants (Zhang et al. 2017).

In addition to using visual cues, whiteflies use specific herbivore-induced plant volatiles (HIPVs) as cues for host selection (Darshanee et al. 2017). It is well established that HIPVs may repel herbivorous insects (Rodriguez-Saona et al. 2003). When attacked by Heliothis virescens, for instance, tobacco plants release several volatile compounds that are highly repellent to conspecific female moths; the compounds are released only at night, which is when the female moths are active (De Moraes et al. 2001). Hatano et al. (2015) found that DMNT, a key plant volatile induced by Spodoptera littoralis larvae, suppressed the sexual behaviors of both males and females of $S$. littoralis. Our current results indicate that MEAM1 showed a strong avoidance of cabbage plants that were previously colonized by conspecifics, which is likely to be mediated by the effects of HIPVs on later-arriving herbivores. Contrary to our results, Silva et al. (2021) reported that tomato plants infested by MEAM1 release a blend of HIPVs that might facilitate subsequent infestation by conspecifics. In another study, infestation by MEAM1 whiteflies caused the host tomato plants to release an inducible blend of volatiles that primed SA-dependent defenses and that suppressed JA-dependent defenses, thus rendering neighboring tomato plants more susceptible to latearriving conspecific whiteflies (Zhang et al. 2019). This unexpected result could be explained by plant species-specific volatiles functioning as key early components leading to expression of defense responses (Holopainen 2004). Additional research is needed to determine whether HIPVs differ qualitatively and quantitatively when cabbage plants are infested by MEAM1 and MED, and whether such differences affect host choice and performance of later-arriving herbivores.

Besides the phenolics and HIPVs, the defensive proteins in herbivore-infested plants also have direct effects on later-arriving herbivores. Proteinase inhibitors (PIs), which impair digestive proteases in the insect midgut, have been well studied for their role in plant defense responses (Koiwa et al. 1997). In comparison with the native spider mite Tetranychus urticae, for instance, the invasive spider mite $T$. evansi can suppress the induction of PIs in tomato plants, and consequently, both spider mites performed much better on plants previously infested by the invasive spider mite than on plants previously infested by the native spider mite or on previously non-infested plants (Sarmento et al. 2011). Cabbage infested 
by MEAM1 could induce the elevated activity of defensive enzymes, such as superoxide dismutase (SOD) and peroxidases (POD), which subsequently deter the cabbage butterfly Pieris rapae (Zhang et al. 2013). Our results showed that the content of free proteins was markedly higher in the MEAM1-infested cabbage plants than in the other two treatments. It seems likely that the free proteins may function as defensive proteins. This possibility might partly explain why MEAM1-infested cabbage plants reduce the settling and performance of later-arriving conspecific whiteflies.

Invasive whitefly species are thought to have various strategies to suppress plant defenses. For example, laccase 1 (LAC1) in the saliva of MED could help the whitefly overcome the host defenses (Yang et al. 2017). Infestation by whiteflies suppressed the JA-regulated volatile emissions induced by spider mites in lima bean and thereby reduced the attraction of predatory mites (Zhang et al. 2009). Among the species complex of $B$. tabaci, MED increases plant susceptibility to attack by later-arriving herbivorous insects. A recent study found that Bt56, a newly discovered salivary effector in MED, can manipulate plant defenses by activating the SA signaling pathway in order to suppress the JA defense pathway (Xu et al. 2019). Su et al. (2018) reported that infestation by MED reduces tomato terpenoid and flavonoid profiles and that MED whiteflies tended to aggregate on conspecific-infested plants. Our present results indicate that cabbage plants previously infested by MED facilitate subsequent attack by MEAM1. These results are in line with the results of Kong et al. (2016), who reported that a significantly higher proportion of MEAM1 settled and oviposited on MED-infested than on non-infested cabbage plants. The observed effects on the preference and performance of whiteflies are consistent with the changes in plant secondary metabolites that play key roles in plant defense against herbivores. In our assays, infestation by MED failed to induce the accumulation of total phenols and flavonoids in cabbage plants. In addition, there were no significant differences in expression levels of PAL2, C4H, and $4 C L 1$ genes between the MEDinfested plants and the non-infested plants, indicating that MED did not trigger such a defensive response in cabbage plants. Unlike infestation by MEAM1, infestation by MED did not increase the contents of total phenols and flavonoids in cabbage plants, which may contribute to the enhanced performance of MEAM1 on plants previously infested by MED.

Host suitability for herbivores is also affected by nutritional quality (Schwachtje and Baldwin 2008). Our biochemical analysis showed that there were no significant differences in the contents of total amino acids, total $\mathrm{N}$, and total $\mathrm{P}$ in non-infested, MEAN1-infested, and MED-infested cabbage plants, indicating that those host nutrients cannot explain why prior infestation by MEAM1 or MED had different effects on the host preference and performance of later-arriving con- and heterospecific whiteflies. Contrary to our results, infestation by MEAM1 resulted in decreased levels of free amino acids in tomato plants, which reduced the fitness of later-arriving whiteflies (Cui et al. 2012). These conflicting results might be explained by difference in the plant species used in the two studies. Another possible explanation for the lack of apparent effects of infestations on host nutrients in the current study is that cabbage plants may have developed more sophisticated mechanisms to balance the trade-offs between growth and defense (Huot et al. 2014). 
In the current study, although more MED settled on non-infested than on infested cabbage plants, MED did not show any preference for settling or ovipositing on MED-infested vs. MEAM1-infested cabbage plants. This result could have at least two explanations. First, the lack of preference may be due to differences in the degree of host specialization. According to the neural constraints hypothesis, generalist herbivores differ from specialists in being deficient in decision-making and in choosing high-quality food (Bernays 1999; Bernays and Minkenberg 1997; Gripenberg et al. 2010). Although both MEAM1 and MED are generalist herbivores, MEAM1 may be more "specialized" than MED (Jiao et al. 2018). Consistent with the reports of Jiao et al. (2012; 2013; 2014), it seems likely that the ability to distinguish between lowquality and high-quality plants may be weaker in MED than in MEAM1. We speculate that MEAM1 whiteflies may be more sensitive to host plant quality than MED whiteflies. Second, cabbage may be a more suitable host for MEAM1 than MED. A number of studies have documented that MEAM1 outperforms MED on cabbage (lida et al. 2009; Sun et al. 2013; Pan et al. 2015; Cui et al. 2017). EPG data also indicates that cabbage is a better host for MEAM1 than MED (Liu et al. 2012; Hu et al. 2019). In addition, it should be noted that the greater variation in cabbage choice by MED than by MEAM1 may to some extent indicate that cabbage is more suitable for MEAM1 than for MED.

In summary, our results provide new insights into the species-specific changes in host-plant metabolism elicited by different herbivores. From an ecological perspective, we found that MED infestation early in the season may facilitate later colonization of cabbage plants by heterospecific MEAM1. In addition, previous infestation by MEAM1 may render the cabbage more resistant to later-arriving conspecifics. Phenolic compounds may be the key factor that mediates the asymmetric effects of pre-infestation on subsequent host choice between MEAM1 and MED. The latter inference is supported by the changes in the expression levels of several marker genes that affect the contents of phenolic compounds in cabbage. From a practical perspective, it is promising for us to employ molecular breeding programs to increase the accumulation of phenolic compounds in the plants, which reduce the infestation of herbivore insects. The results also allow us to infer the sequence of attacks of cabbage when both MEAM1 and MED are present, which could assist in the development of pest-management strategies.

\section{Declarations}

\section{Acknowledgments}

This study was funded by the National Natural Science Foundation of China $(31371941,31572012)$.

\section{Author contribution statement}

XGJ and YJZ designed the experiment. JH, JTL, BML, and PYF performed the experiment. XGJ and NNY analyzed the data. $\mathrm{JH}, \mathrm{XGJ}$, and $\mathrm{YJZ}$ wrote the paper. All authors read and approved the manuscript.

Conflict of interest: The authors declare no conflict of interest.

\section{References}


1. Aqueel MA, Collins CM, Raza ABM, Ahmad S, Tariq M, Leather SR (2014) Effect of plant nutrition on aphid size, prey consumption, and life history characteristics of green lacewing. Insect Sci 21:74-82

2. Awmack CS, Leather SR (2002) Host plant quality and fecundity in herbivorous insects. Annu Rev Entomol 47:817-844

3. Beckers GJM, Spoel SH (2006) Fine-tuning plant defence signalling: salicylate versus jasmonate. Plant biology 8:1-10

4. Bernays EA (1999) When host choice is a problem for a generalist herbivore: experiments with the whitefly Bemisia tabaci. Ecol Entomol 24:260-267

5. Bernays EA, Minkenberg $O$ (1997) Insect herbivores: different reasons for being a generalist. Ecology 78:1157-1169

6. Chen MS (2008) Inducible direct plant defense against insect herbivores: a review. Insect Sci 15:101-114

7. Close DC, Mcarthur C (2002) Rethinking the role of many plant phenolics:Protection from photodamage not herbivores? Oikos 99:166-172

8. Cui HY, Guo LT, Wang SL, Xie W, Jiao XG, Wu QJ, Zhang YJ (2017) The ability to manipulate plant glucosinolates and nutrients explains the better performance of Bemisia tabaci Middle East-Asia Minor 1 than Mediterranean on cabbage plants. Ecol Evol 7:6141-6150

9. Cui HY, Sun YC, Su JW, Li CY, Ge F (2012) Reduction in the fitness of Bemisia tabaci fed on three previously infested tomato genotypes differing in the jasmonic acid pathway. Environ Entomol 41:1443-1453

10. Darshanee HL, Ren H, Ahmed N, Zhang ZF, Liu YH, Liu TX (2017) Volatile-mediated attraction of greenhouse whitefly Trialeurodes vaporariorum to tomato and eggplant. Front Plant Sci 8:1285

11. De Moraes CM, Mescher MC, Tumlinson JH (2001) Caterpillar-induced nocturnal plant volatiles repel conspecific females. Nature 410:577-580

12. De Geyter N, Gholami A, Goormachtig S, Goossens A (2012) Transcriptional machineries in jasmonate-elicited plant secondary metabolism. Trends Plant Sci 17:349-359

13. De Vos M, Jander G (2009) Myzus persicae (green peach aphid) salivary components induce defence responses in Arabidopsis thaliana. Plant Cell Environ 32:1548-1560

14. Dinsdale A, Cook L, Riginos C, Buckley YM, De Barro P (2010) Refined global analysis of Bemisia tabaci (Hemiptera: Sternorrhyncha: Aleyrodoidea: Aleyrodidae) mitochondrial cytochrome oxidase 1 to identify species level genetic boundaries. Ann Entomol Soc Am 103:196-208

15. Dixon RA, Achnine L, Kota P, Liu CJ, Reddy MSS, Wang LJ (2002) The phenylpropanoid pathway and plant defence-a genomics perspective. Mol Plant Pathol 3:371-390

16. Dudareva N, Klempien A, Muhlemann JK, Kaplan I (2013) Biosynthesis, function and metabolic engineering of plant volatile organic compounds. New Phytol 198:16-32

17. Erb M, Meldau S, Howe GA (2012) Role of phytohormones in insect-specific plant reactions. Trends Plant Sci 17:250-259 
18. Erb M, Robert CAM, Hibbard BE, Turlings TCJ (2011) Sequence of arrival determines plant-mediated interactions between herbivores. J Ecol 99:7-15

19. Esterhuizen LL, Mabasa KG, van Heerden SW, Czosnek H, Brown JK, van Heerden H, Rey MEC (2013) Genetic identification of members of the Bemisia tabaci cryptic species complex from South Africa reveals native and introduced haplotypes. J Appl Entomol 137:122-135

20. Ferry N, Edwards MG, Gatehouse JA, Gatehouse JA (2004) Plant-insect interactions: molecular approaches to insect resistance. Curr Opin Biotech 15:155-161

21. Gripenberg S, Mayhew PJ, Parnell M, Roslin T (2010) A meta-analysis of preference-performance relationships in phytophagous insects. Ecol Lett 13:383-393

22. Hatano E, Saveer AM, Borrero-Echeverry F, Strauch M, Zakir A, Bengtsson M, Ignell R, Anderson P, Becher PG, Witzgall P, Dekker T (2015) A herbivore-induced plant volatile interferes with host plant and mate location in moths through suppression of olfactory signalling pathways. BMC Biol 13:115

23. Holopainen JK (2004) Multiple functions of inducible plant volatiles. Trends Plant Sci 9:529-533

24. Hopkins RJ, van Dam NM, van Loon JJA (2009) Role of glucosinolates in insect-plant relationships and multitrophic interactions. Annu Rev Entomol 54:57-83

25. Howe GA, Jander G (2008) Plant immunity to insect herbivores. Annu Rev Plant Biol 59:41-66

26. Huot B, Yao J, Montgomery BL, He SY (2014) Growth-defense tradeoffs in plants: a balancing act to optimize fitness. Mol Plan 7:1267-1287

27. Hu J, Yang JJ, Liu BM, Cui HY, Zhang YJ, Jiao XG (2020) Feeding behavior explains the different effects of cabbage on MEAM1 and MED cryptic species of Bemisia tabaci. Insect Sci 27:1276-1284

28. lida H, Kitamura T, Honda K (2009) Comparison of egg-hatching rate, survival rate and development time of the immature stage between B- and Q-biotypes of Bemisia tabaci (Gennadius) (Homoptera: Aleyrodidae) on various agricultural crops. Appl Entomol Zool 44:267-273

29. Inbar M, Doostdar H, Mayer RT (1999) Effects of sessile whitefly nymphs (Homoptera: Aleyrodidae) on leaf-chewing larvae (Lepidoptera: Noctuidae). Environ Entomol 28:353-357

30. Inbar M, Gerling D (2008) Plant-mediated interactions between whiteflies, herbivores, and natural enemies. Annu Rev Entomol 53:431-448

31. Jiao XG, Xie W, Guo LT, Liu BM, Wang SL, Wu QJ, Zhang YJ (2014) Differing effects of cabbage and pepper on B and Q putative species of Bemisia tabaci. J Pest Sci 87:629-637

32. Jiao XG, Xie W, Wang SL, Wu QJ, Pan HP, Liu BM, Zhang YJ (2013) Differences in host selection and performance between B and Q putative species of Bemisia tabacion three host plants. Entomol Exp Appl 147:1-8

33. Jiao XG, Xie W, Wang SL, Wu QJ, Zhou L, Pan HP, Liu BB, Zhang YJ (2012) Host preference and nymph performance of B and Q putative species of Bemisia tabacion three host plants. J Pest Sci 85:423-430 
34. Jiao XG, Xie W, Zeng Y, Wang C, Liu BM, Wang SL, Wu QJ, Zhang YJ (2018) Lack of correlation between host choice and feeding efficiency for the B and Q putative species of Bemisia tabacion four pepper genotypes. J Pest Sci 91:133-143

35. Karban R, Agrawal AA (2002) Herbivore offense. Annu Rev Ecol Syst 33:641-664

36. Karban R, Baldwin IT (1997) Induced responses to herbivory. University of Chicago Press, Chicago

37. Kempema LA, Cui X, Holzer FM, Walling LL (2007) Arabidopsis transcriptome changes in response to phloem-feeding silverleaf whitefly nymphs. Similarities and distinctions in responses to aphids. Plant Physiol 143:849-865

38. Kessler A, Baldwin IT (2002) Plant responses to insect herbivory: the emerging molecular analysis. Annu Rev Plant Biol 53:299-328

39. Kessler A, Halitschke R (2007) Specificity and complexity: the impact of herbivore-induced plant responses on arthropod community structure. Curr Opin Plant Biol 10:409-414

40. Koiwa H, Bressan RA, Hasegawa PM (1997) Regulation of protease inhibitors and plant defense. Trends Plant Sci 2:379-384

41. Kong HL, Zeng Y, Xie W, Wang SL, Wu QJ, Jiao XG, Xu BY, Zhang YJ (2016) Differing behavioural responses of Bemisia tabaci MEAM1 and MED to cabbage damaged by conspecifics and heterospecifics. Scientific reports 6:1-6

42. Koornneef A, Pieterse CMJ (2008) Cross talk in defense signaling. Plant Physiol 146:839-844

43. Liu BM, Yan FM, Chu D, Pan HP, Jiao XG, Xie W, Wu QJ, Wang SL, Xu BY, Zhou XG, Zhang YJ (2012) Difference in feeding behaviors of two invasive whiteflies on host plants with different suitability: implication for competitive displacement. Int J Biol Sci 8:697-706

44. Li J, Qian HM, Pan LL, Wang QM, Liu SS (2021) Performance of two species of whiteflies is unaffected by glucosinolate profile in Brassica plants. Pest Manag Sci. https://doi.org/10.1002/ps.6460

45. Lu ZX, Yu XP, Heong KL, Hu C (2007) Effect of nitrogen fertilizer on herbivores and its stimulation to major insect pests in rice. Rice Sci 14:56-66

46. Mauch-Mani B, Baccelli I, Luna E, Flors V (2017) Defense priming: an adaptive part of induced resistance. Annu Rev Plant Biol 68:485-512

47. Oliveira MRV, Henneberry TJ, Anderson P (2001) History, current status, and collaborative research projects for Bemisia tabaci. Crop Prot 20:709-723

48. Pan HP, Preisser EL, Chu D, Wang SL, Wu QJ, Carrière Y, Zhou XG, Zhang YJ (2015) Insecticides promote viral outbreaks by altering herbivore competition. Ecol Appl 25:1585-1595

49. Pieterse CMJ, Van der Does D, Zamioudis C, Leon-Reyes A, Van Wees SCM (2012) Hormonal modulation of plant immunity. Annu Rev Cell Dev Bi 28:489-521

50. Poelman EH, Broekgaarden C, Van Loon JJA, Dicke M (2008) Early season herbivore differentially affects plant defence responses to subsequently colonizing herbivores and their abundance in the field. Mol Ecol 17:3352-3365 
51. Poelman EH, Dicke M (2014) Plant-mediated interactions among insects within a community ecological perspective. Annu Plant Rev 47:309-337

52. Rodriguez-Saona C, Crafts-Brandner SJ, Cañas LA (2003) Volatile emissions triggered by multiple herbivore damage: beet armyworm and whitefly feeding on cotton plants. J Chem Ecol 29:25392550

53. Sarmento RA, Lemos F, Bleeker PM, Schuurink RC, Pallini A, Oliveira MGA, Lima ER, Kant R, Sabelis MW, Janssen A (2011) A herbivore that manipulates plant defence. Ecol Lett 14:229-236

54. Schuman MC, Baldwin IT (2016) The layers of plant responses to insect herbivores. Annu Rev Entomol 61:373-394

55. Schwachtje J, Baldwin IT (2008) Why does herbivore attack reconfigure primary metabolism? Plant Physiol 146:845-851

56. Silva DB, Jiménez A, Urbaneja A, Pérez-Hedo M, Bento JM (2021) Changes in plant responses induced by an arthropod influence the colonization behavior of a subsequent herbivore. Pest Manag Sci. https://doi.org/10.1002/ps.6454

57. Stahl E, Hilfiker O, Reymond P (2018) Plant-arthropod interactions: who is the winner? Plant J 93:703-728

58. Stam JM, Kroes A, Li Y, Gols R, van Loon JJA, Poelman EH, Dicke M (2014) Plant interactions with multiple insect herbivores: from community to genes. Annu Rev Plant Biol 65:689-713

59. Sun DB, Liu YQ, Qin L, Xu J, Li FF, Liu SS (2013) Competitive displacement between two invasive whiteflies: insecticide application and host plant effects. B Entomol Res 103:344-353

60. Su Q, Chen G, Mescher MC, Peng ZK, Xie W, Wang SL, Wu QJ, Liu J, Li CR, Wang WK, Zhang YJ (2018) Whitefly aggregation on tomato is mediated by feeding-induced changes in plant metabolites that influence the behaviour and performance of conspecifics. Funct Ecol 32:1180-1193

61. Visanuvimol L, Bertram SM (2010) Dietary phosphorus availability influences female cricket lifetime reproductive effort. Ecol Entomol 35:386-395

62. Viswanathan DV, Lifchits OA, Thaler JS (2007) Consequences of sequential attack for resistance to herbivores when plants have specific induced responses. Oikos 116:1389-1399

63. Walling LL (2008) Avoiding effective defenses: strategies employed by phloem-feeding insects. Plant Physiol 146:859-866

64. Walling LL (2000) The myriad plant responses to herbivores. J Plant Growth Regul 19:195-216

65. Xu HX, Qian LX, Wang XW, Shao RX, Hong Y, Liu SS, Wang XW (2019) A salivary effector enables whitefly to feed on host plants by eliciting salicylic acid-signaling pathway. P Natl Acad Sci USA 116:490-495

66. Xue M, Wang CX, Bi MJ, Li QL, Liu TX (2010) Induced defense by Bemisia tabaci biotype B (Hemiptera: Aleyrodidae) in tobacco against Myzus persicae (Hemiptera: Aphididae). Environ Entomol 39:883-891 
67. Yang CH, Guo JY, Chu D, Ding TB, Wei KK, Cheng DF, Wan FH (2017) Secretory laccase 1 in Bemisia tabaci MED is involved in whitefly-plant interaction. Scientific reports 7:1-9

68. Yang JJ, Xie W, Liu BM, Wang SL, Wu QJ, He YC, Zhang YJ, Jiao XG (2020) Phenolics, rather than glucosinolates, mediate host choice of Bemisia tabaci MEAM1 and MED on five cabbage genotypes. J Appl Entomol 144:287-296

69. Zarate SI, Kempema LA, Walling LL (2007) Silverleaf whitefly induces salicylic acid defenses and suppresses effectual jasmonic acid defenses. Plant Physiol 143:866-875

70. Zhang GF, Lövei GL, Hu M, Wan FH (2014) Asymmetric consequences of host plant occupation on the competition between the whiteflies Bemisia tabacicryptic species MEAM1 and Trialeurodes vaporariorum (Hemiptera: Aleyrodidae). Pest Manag Sci 70:1797-1807

71. Zhang PJ, Li WD, Huang F, Zhang MJ, Xu FC, Lu YB (2013) Feeding by whiteflies suppresses downstream jasmonic acid signaling by eliciting salicylic acid signaling. J Chem Ecol 39:612-619

72. Zhang PJ, Wei JN, Zhao C, Zhang YF, Li CY, Liu SS, Dicke M, Yu XP, Turlings TCJ (2019) Airborne host-plant manipulation by whiteflies via an inducible blend of plant volatiles. P Natl Acad Sci USA 116:7387-7396

73. Zhang PJ, Xu CX, Zhang JM, Lu YB, Wei JN, Liu YQ, David A, Boland W, Turlings TCJ (2013) Phloemfeeding whiteflies can fool their host plants, but not their parasitoids. Funct Ecol 27:1304-1312

74. Zhang PJ, Zheng SJ, van Loon JJA, Boland W, David A, Mumm R, Dicke M (2009) Whiteflies interfere with indirect plant defense against spider mites in Lima bean. P Natl Acad Sci USA 106:2120221207

75. Zhang SZ, Huang H, Shan HW, Zhang F, Wan FH, Liu TX (2013) Defense against Pieris rapae in cabbage plants induced by Bemisia tabaci biotype B. Entomol Exp Appl 147:293-300

76. Zhang X, Sun X, Zhao HP, Xue M, Wang D (2017) Phenolic compounds induced by Bemisia tabaci and Trialeurodes vaporariorum in Nicotiana tabacum $\mathrm{L}$. and their relationship with the salicylic acid signaling pathway. Arthropod-Plant Inte 11:659-667

77. Zhao HP, Zhang XY, Xue M, Zhang X (2015) Feeding of whitefly on tobacco decreases aphid performance via increased salicylate signaling. PLoS One 10:e0138584

\section{Figures}



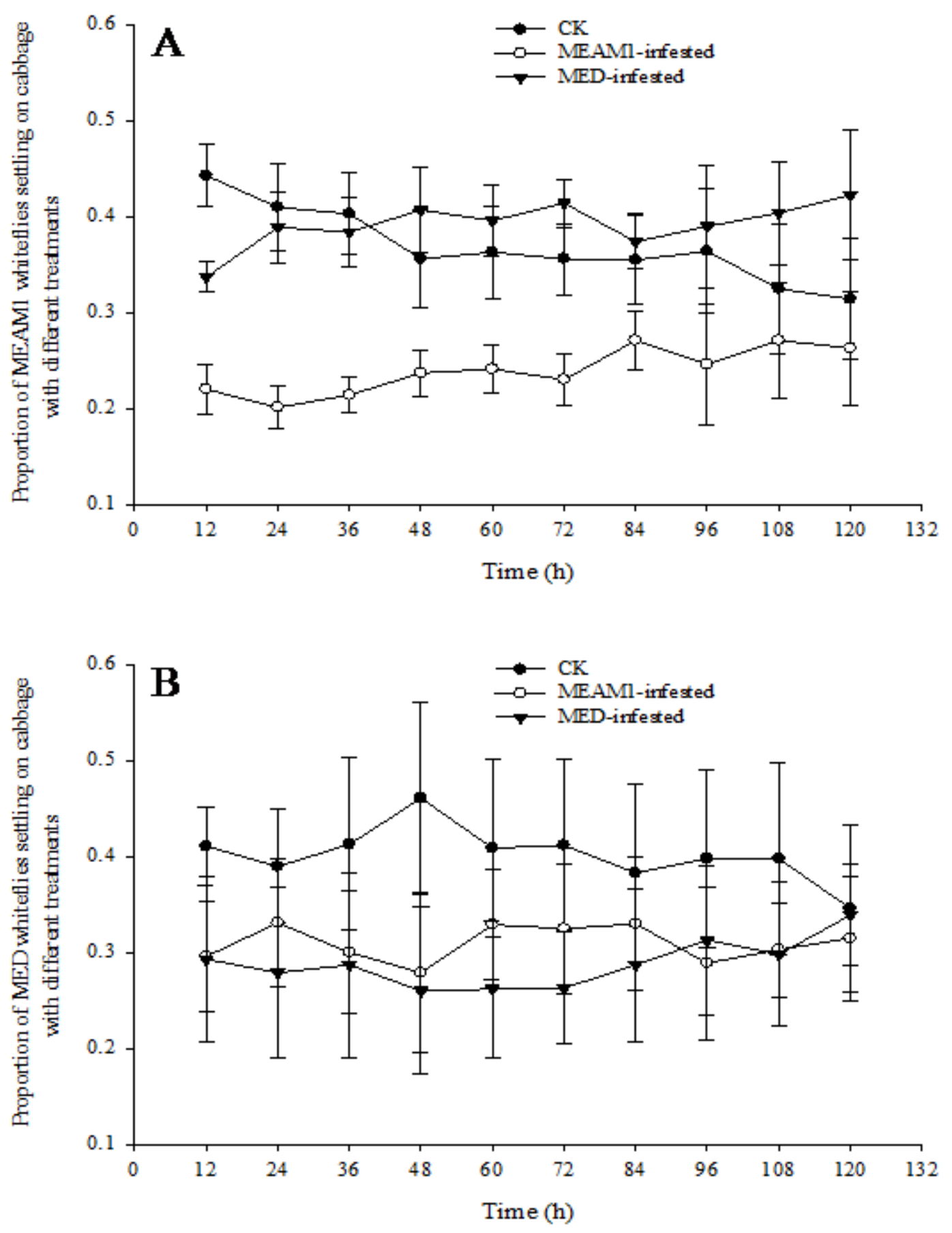

Figure 1

Host choices (as indicated by settling) of MEAM1 (A) and MED (B) cryptic species of Bemisia tabaci on non-infested (CK), MEAM1-infested, and MED-infested cabbage plants. Values are means + SE. 

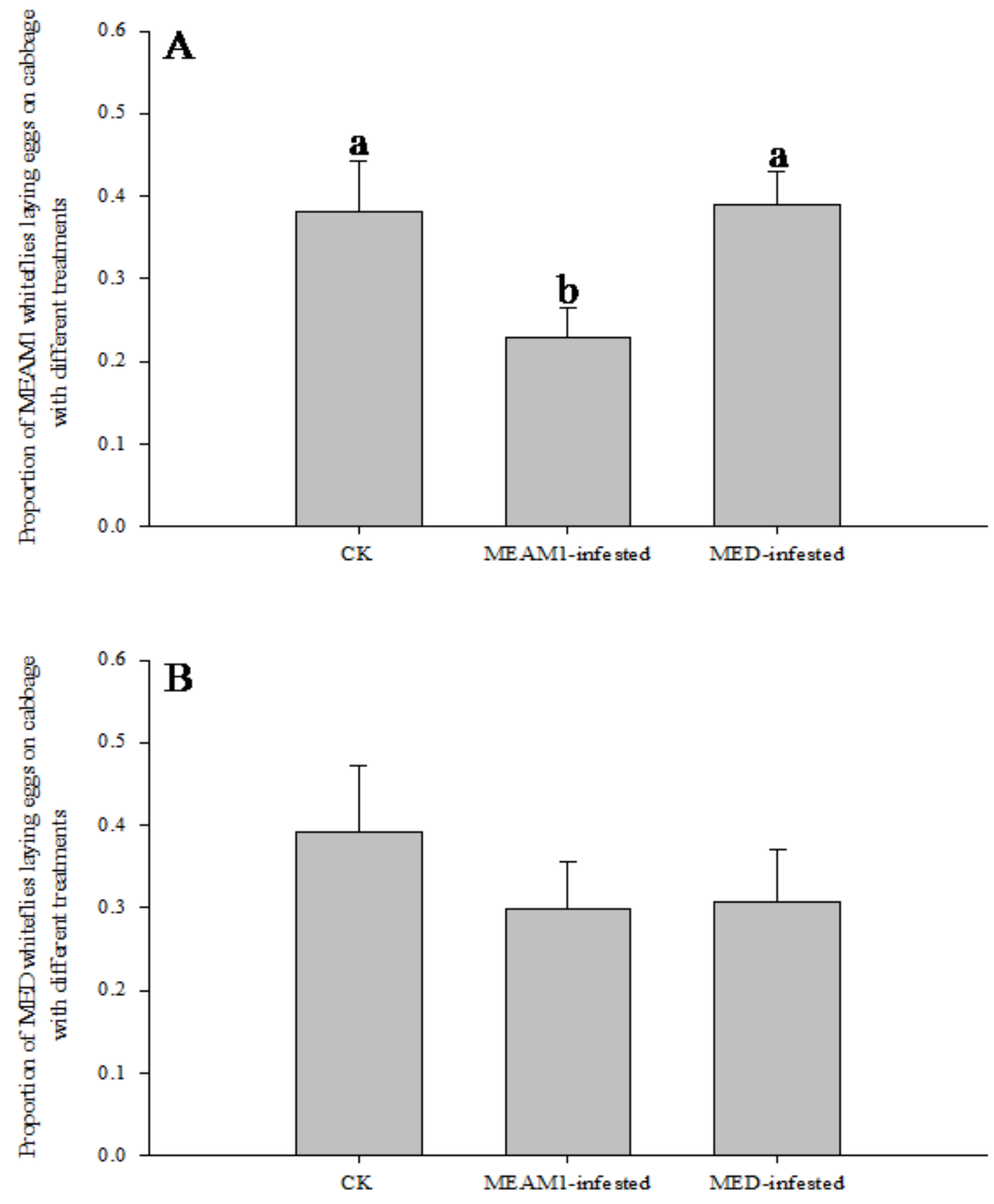

Figure 2

Egg-laying choices of MEAM1 (A) and MED (B) cryptic species of Bemisia tabaci on non-infested (CK), MEAM1-infested, and MED-infested cabbage plants. Values are means + SE. Means with different letters are significantly different $(P<0.01)$. 

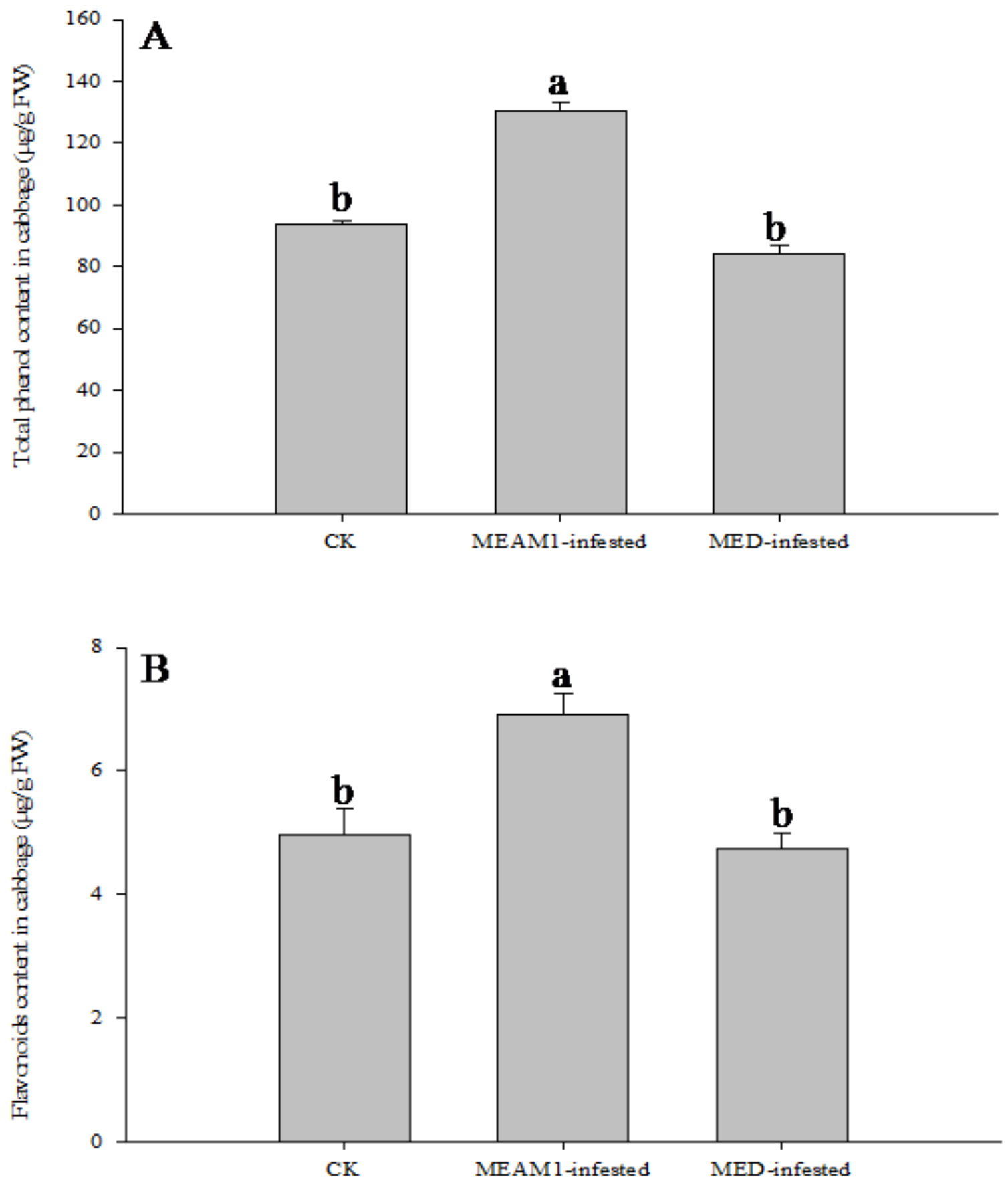

Figure 3

Contents of total phenols (A) and flavonnoids (B) in non-infested (CK), MEAM1-infested, and MEDinfested cabbage plants. Values are means $+\mathrm{SE}$. Means with different letters are significantly different $(P$ $<0.01)$. 

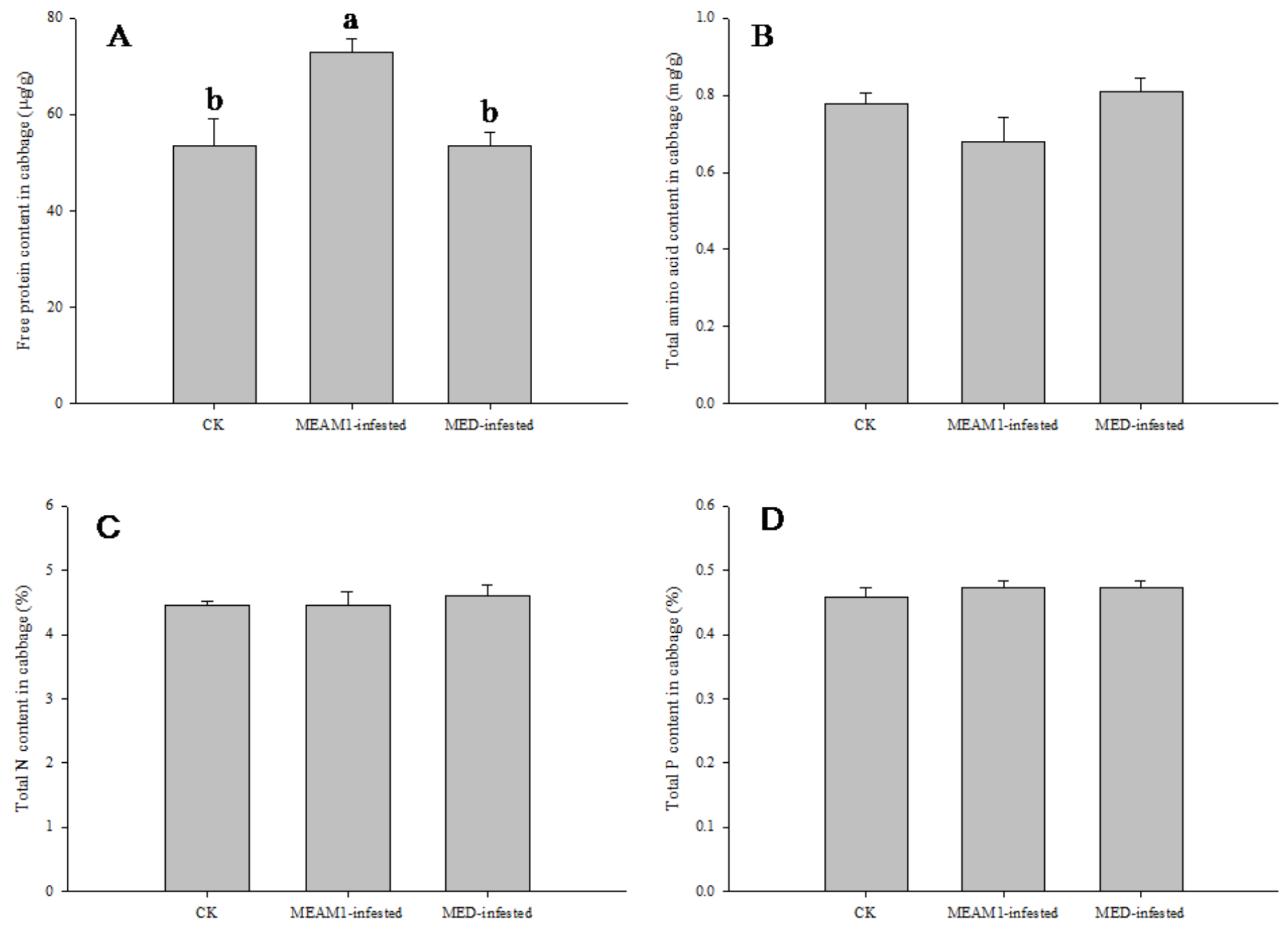

Figure 4

Contents of free proteins (A), total amino acids (B), total nitrogen (C), and total phosphorus (D) in noninfested (CK), MEAM1-infested, and MED-infested cabbage plants. Values are means + SE. Means with different letters are significantly different $(P<0.01)$. 

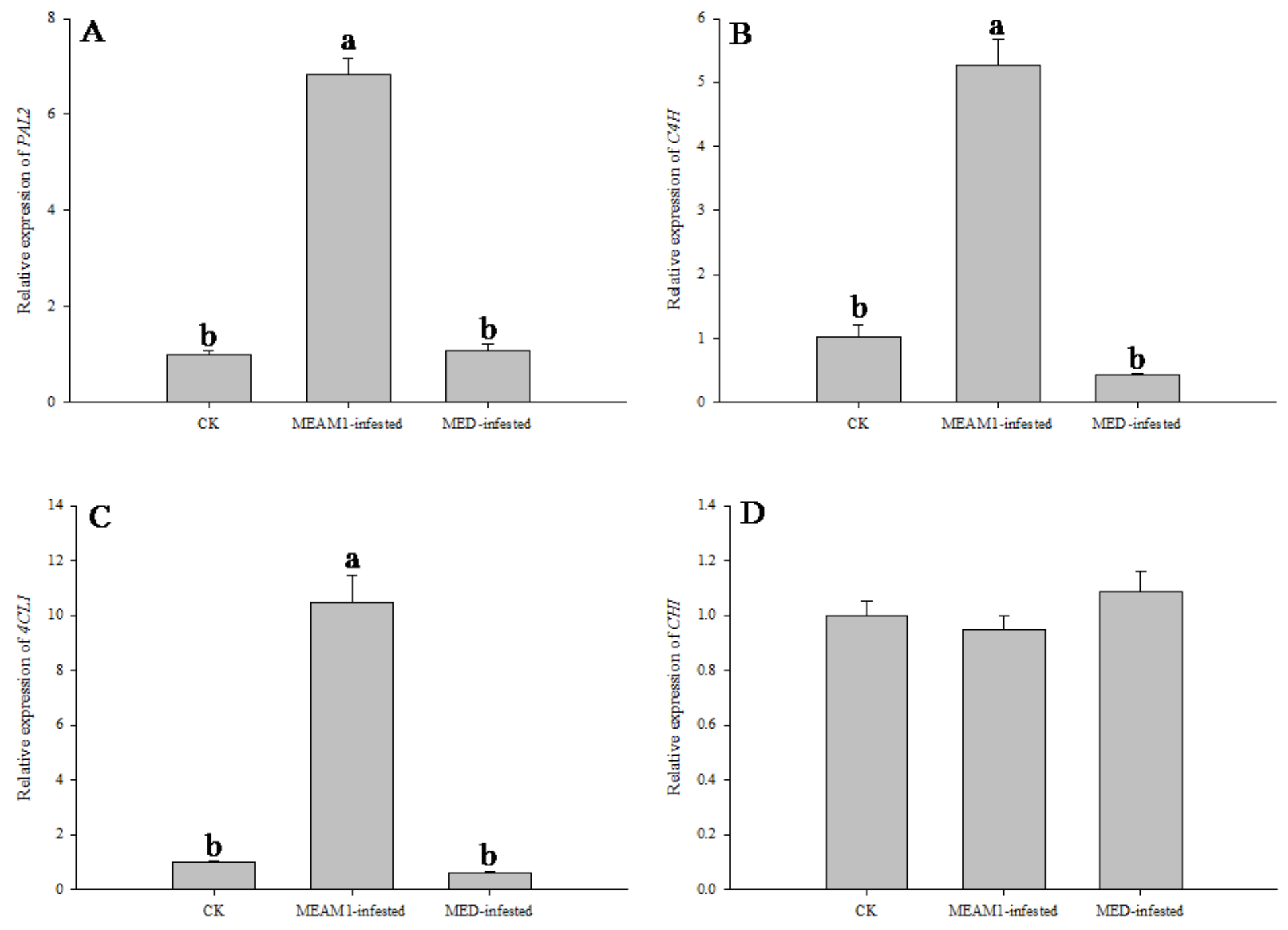

Figure 5

Relative expressions of the genes PAL2 (A), C4H (B), 4CL1 (C), and CHI (D) in non-infested (CK), MEAM1infested, and MED-infested cabbage plants. Values are means + SE. Means with different letters are significantly different $(P<0.01)$. 